\title{
The management strategies of cancer- associated anorexia: a critical appraisal of systematic reviews
}

\author{
Zhang Fangyuan', Shen Aomei ${ }^{1}$, Jin Yinghui ${ }^{2}$ and Qiang Wanmin ${ }^{1 *}$ (D)
}

\begin{abstract}
Background: Cancer-related anorexia remains one of the most prevalent and troublesome clinical problems experienced by patients with cancer during and after therapy. To ensure high-quality care, systematic reviews (SRs) are seen as the best guide. Considering the methodology quality of SRs varies, we undertook a comprehensive overview, and critical appraisal of pertinent SRs.
\end{abstract}

Methods: Eight databases (between the inception of each database and September 1, 2017) were searched for SRs on the management of cancer-related anorexia. Two researchers evaluated the methodological quality of each SR by using the Revised Assessment of Multiple Systematic Reviews (R-AMSTAR) checklist. Characteristics of the "high quality" SRs were abstracted, included information on relevant studies numbers, study design, population, intervention, control, outcome and result.

Results: Eighteen SRs met the inclusion criteria. The R-AMSTAR scores of methodological quality ranged from 18 to 41 out of 44 , with an average score of 30 . Totally eight SRs scored $\geq 31$ points, which showed high methodological quality, and would be used for data extraction to make summaries. Anamorelin had some positive effects to relieve cancer anorexia-cachexia syndrome (CACS) and improve the quality of life (QoL). Megestrol Acetate (MA) could improve appetite, and was associated with slight weight gain for CACS. Oral nutritional interventions were effective in increasing nutritional intake and improving some aspects of QoL in patients with cancer who were malnourished or at nutritional risk. The use of thalidomide, Eicosapentaenoic Acid, and minerals, vitamins, proteins, or other supplements for the treatment of cachexia in cancer were uncertain, and there was inadequate evidence to recommend it to clinical practices, the same situation in Chinese Herb Medicine and acupuncture (acupuncture and related therapies were effective in improving QoL) for treating anorexia in cancer patients, warranting further RCTs in these areas.

Conclusions: Anamorelin, MA, oral nutrition interventions, and acupuncture could be considered to be applied in patients with cancer-related anorexia. Future RCTs and SRs with high quality on the pharmaceutical or non-pharmaceutical interventions of anorexia in cancer patients are warranted.

Keywords: Evidence-based medicine, Cancer, Anorexia, Systematic review, Meta-analysis

\footnotetext{
* Correspondence: wmaiang213@126.com

${ }^{1}$ Tianjin Medical University Cancer Institute and Hospital, National Clinical

Research Center for Cancer; Key Laboratory of Cancer Prevention and

Therapy, Tianjin; Tianjin's Clinical Research Center for Cancer, Tianjin, CN, Hexi

District, 1 West Lake Road, Tianjin, China

Full list of author information is available at the end of the article
}

(c) The Author(s). 2018 Open Access This article is distributed under the terms of the Creative Commons Attribution 4.0 International License (http://creativecommons.org/licenses/by/4.0/), which permits unrestricted use, distribution, and reproduction in any medium, provided you give appropriate credit to the original author(s) and the source, provide a link to the Creative Commons license, and indicate if changes were made. The Creative Commons Public Domain Dedication waiver (http://creativecommons.org/publicdomain/zero/1.0/) applies to the data made available in this article, unless otherwise stated. 


\section{Background}

Cancer is the second leading cause of death worldwide, Global Burden of Disease Cancer Collaboration reported that there were 17.5 million cancer cases around the world and 8.7 million deaths in 2015; cancer cases increased by $33 \%$ during the last decade [1]. Towards the end of life, individuals with cancer experience substantial symptom burden [2, 3]. The top three common symptoms in patients with cancer at the end of life are fatigue, pain, and anorexia (appetite loss) [4, 5]. Anorexia is defined as loss of appetite with or without weight loss, which occurs in half of newly diagnosed cancer patients and $26.8 \% \sim 57.9 \%$ of patients with advanced cancer $[3,6]$. Cancer-related anorexia is a major clinical problem, and adversely influences nutritional status of patients, which may negatively impact patients' quality of life and increase the burden on healthcare resources [7]. It is also upsetting to both patients and their caregivers, who need supportive care from healthcare professionals [8]. Besides, anorexia is one of the independent prognostic factors for survival [9]. Thus, scientific and effective management strategies for cancer-related anorexia are urgently needed.

Systematic reviews (SRs) provide an opportunity to base decisions on accurate, succinct, credible, and comprehensive summaries of the best available evidence on a specific topic, and act as one of the key tools for healthcare professionals to achieve evidence based decisions [10]. To date, several SRs on the management of anorexia in cancer patients have been published. Considering the methodology quality of SRs varies, and uncritically accepting the results of a systematic review has a risk. Therefore, we sought to conduct a comprehensive overview, and critical appraisal of pertinent SRs to better characterize the management strategies of cancer-related anorexia, based on SRs with high methodological quality.

\section{Methods}

\section{Identification of studies}

The following electronic databases were systematically searched for SRs: PubMed, Embase, The Cochrane library, CINAHL, JBI, China National Knowledge Infrastructure (CNKI), Chinese Bio-medical Literature Database (CBM), and WanFang Database. Articles published in English and Chinese between the inception of each database and September 1, 2017, were searched for controlled vocabulary terms specific to each database related to neoplasms, anorexia, systematic reviews, meta analysis. Detailed search strategies were provided in Additional file 1. The references of SRs included were also manually reviewed.

\section{Eligibility criteria}

We defined the following inclusion criteria: (1) Population: Adults with cancer (all sites and stages) suffering from anorexia or symptoms indicative of anorexia, such as lack of appetite, weight loss, poor performance status, and diminished quality of life [6]; (2) Interventions: Pharmaceutical or non-pharmaceutical treatments, such as exercises, oral nutrition intervention, acupuncture, in cancer patients with anorexia; (3) Included studies: At least 2 studies, either randomized clinical trials (RCTs) or observational studies; (4) Design: Systematic review/ meta-analysis in accordance with Cochrane Collaboration; and (5) Form: Full texts available. Exclusion criteria included: (1) Population: Animals, children with cancer, or non-cancer patients. (2) Interventions: Qualitative researches on experience or psychosocial effect of anorexia in cancer patients; (3) Design: Protocol, overview of SRs, narrative review, expert review, scoping review.

\section{Selection of studies}

Two researchers (FY, AM) assessed the eligibility of all SRs independently. For the process, titles and abstracts were reviewed firstly; then full-text articles were reviewed to judge the eligibility. Full texts that did not fulfill the priori defined inclusion criteria were excluded. Disagreements regarding inclusion in the final review were resolved through discussion and consensus. A third researcher $(\mathrm{YH})$ was consulted if the disagreements cannot be resolved between the two researchers.

\section{Methodological quality of studies and data extraction}

Two researchers (FY, AM) evaluated the methodological quality of each SR by using the Revised Assessment of Multiple Systematic Reviews (R-AMSTAR) checklist, a tool with 11 items [11]. The R-AMSTAR items were scored with a range of one to four points with higher scores indicating better methodological quality. The total score on R-AMSTAR was 44 points, and the minimum score is 11points. Any disagreements between the researchers regarding to the methodological quality of included SRs were resolved in a consensus-building discussion, if necessary by a third researcher $(\mathrm{YH})$. Besides, only those with the R-AMSTAR score $\geq 31$ points, defined as "high quality", were taken into consideration $[12,13]$.

Characteristics of the included "high quality" SRs were abstracted independently by two researchers (FY, AM), and disagreements were resolved through discussion and consensus. Abstracted data was included information on relevant studies numbers, study design, population, intervention, control, and outcome. As for SRs with the same intervention, the latest one with better methodological quality would be included for analysis. 


\section{Results}

\section{Study selection}

The review identification and selection procedures are outlined in Fig. 1. Of 1634 initially identified search hits, 159 duplications were excluded, and 1475 records remained for citation screening. After the screening of titles and abstracts, 80 full texts were retrieved for eligibility assessment. Among them, 62 publications were excluded because of the following reasons: irrelevant population $(n$ $=1)$, irrelevant interventions $(n=11)$, insufficient studies included $(n=2)$, inadequate design $(n=44)$, inadequate form $(n=3)$, irrelevant language $(n=1)$. As a result, 18 SRs met the predefined eligibility criteria were included $[6,14-30]$.

\section{Methodological quality}

Results of the critical appraisal for 18 SRs using R-AMSTAR are presented in Table 1 . The R-AMSTAR scores of methodological quality ranged from 18 to 41 out of 44, with an average score of 30. Totally 8 SRs (Dewey et al., 2007; Baldwin et al., 2012; Reid et al., 2012; Ruiz et al., 2013; Chung et al., 2016; Lau et al., 2016; Mochamat et al., 2017; Bai et al., 2017) [17, 19-21, 26-29] scored $\geq 31$ points, which showed high methodological quality, and would be used for data extraction to make a summary. Most SRs provided "a priori" design, i.e., a protocol, a research question and inclusion criteria (mean: 3.33). In contrast, the criteria of items such as "quality of included studies assessed and documented" (mean: 2.06), "scientific quality used appropriately in formulating conclusions" (mean: 1.22), and "conflict of interest stated" (mean: 2.33) were completely satisfied only by one SR. The items of "list of studies included and excluded", and "likelihood of publication bias assessed" were also insufficient in several reviews.

\section{Summaries of SRs with high methodological quality}

Table 2 describes the general characteristics of 8 included SRs with high methodological quality. The management strategies of cancer related anorexia included drugs $(n=3)[20,21,28]$, dietary or nutritional intervention $(n=3)[17,19,29]$, Chinese Herbal Medicine (CHM, $n=1)$ [26], acupuncture $(n=1)$ [27].

\section{Acupuncture}

Compared with conventional interventions, acupuncture and related therapies improved quality of life in patients with gastrointestinal cancer $(n=111$, pooled SMD: 0.75 , 95\% CI: 0.36 1.13); Acupuncture and related therapies also showed improvement in anorexia, but there was no statistical significance $(n=50, \mathrm{RR}: 2.51,95 \% \mathrm{CI}: 0.94 \sim$ 6.72); Besides, acupuncture and related therapies significantly reduced pain $(n=175$, pooled WMD: $-0.76,95 \%$ CI: $-0.14 \sim-0.39)$ in patients with liver or gastric cancer, and fatigue ( $n=57$, MD: $-0.63,95 \% \mathrm{CI}:-1.22 \sim-0.44)$ in

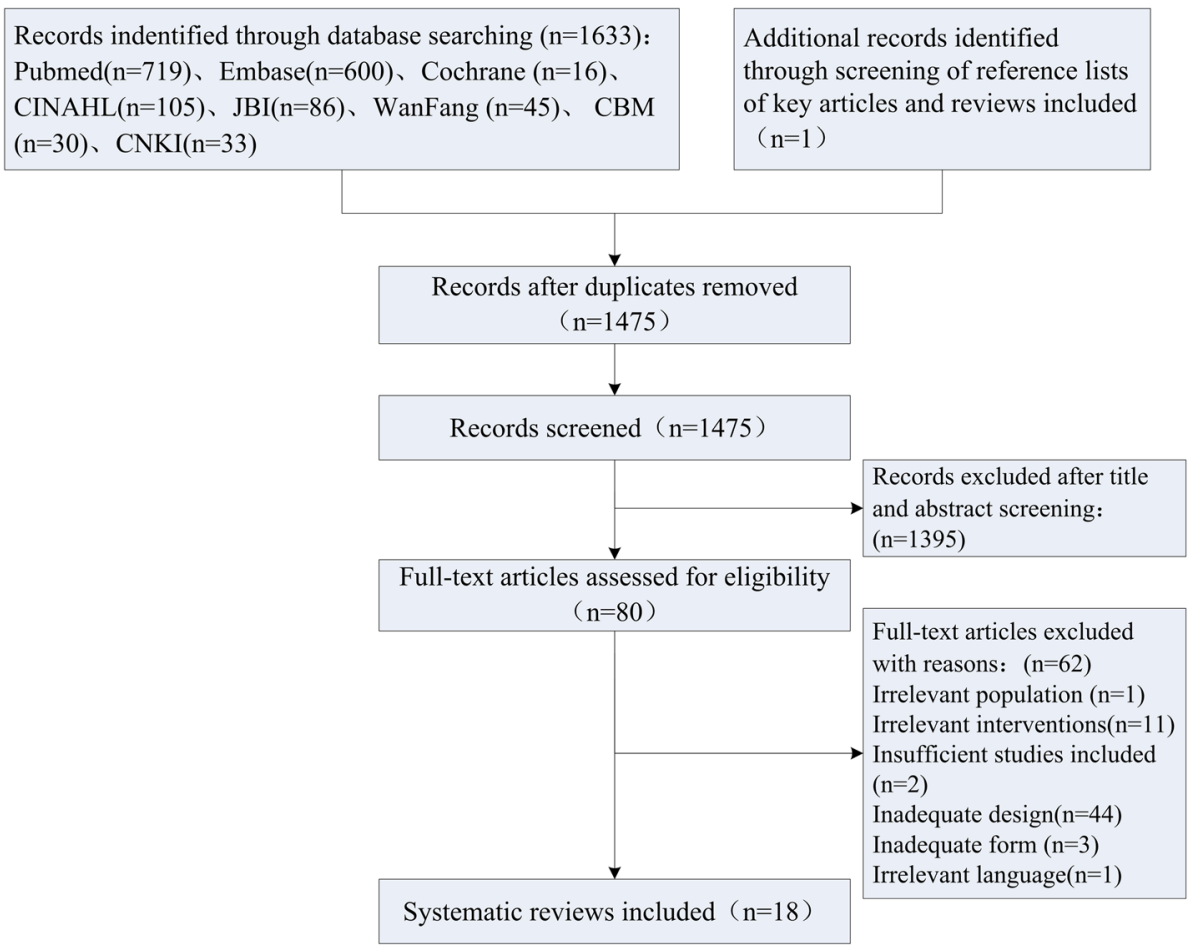

Fig. 1 Flowchart of the systematic review selection procedure 
Chang et al. BMC Complementary and Alternative Medicine (2018) 18:236

Page 4 of 9

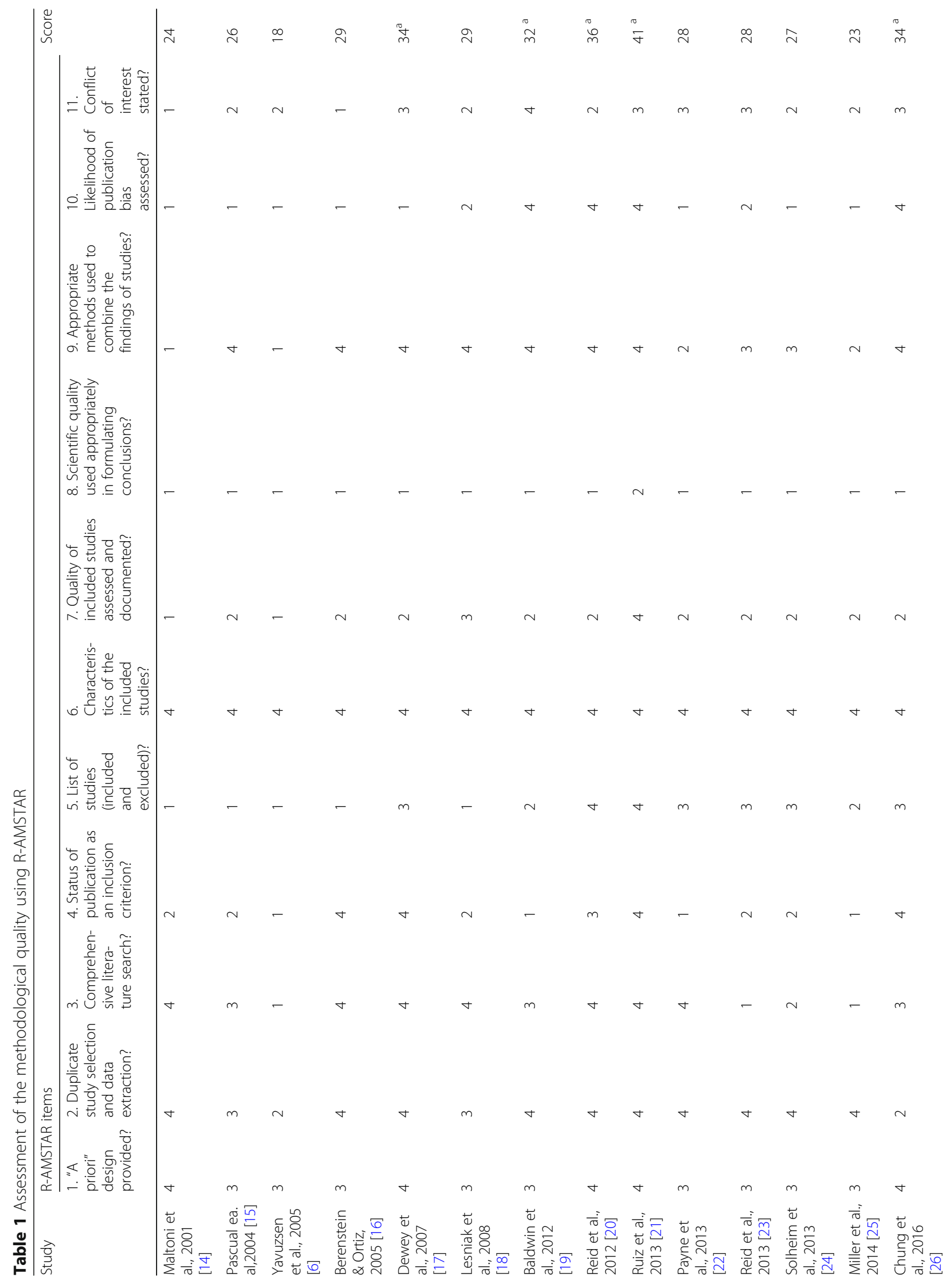




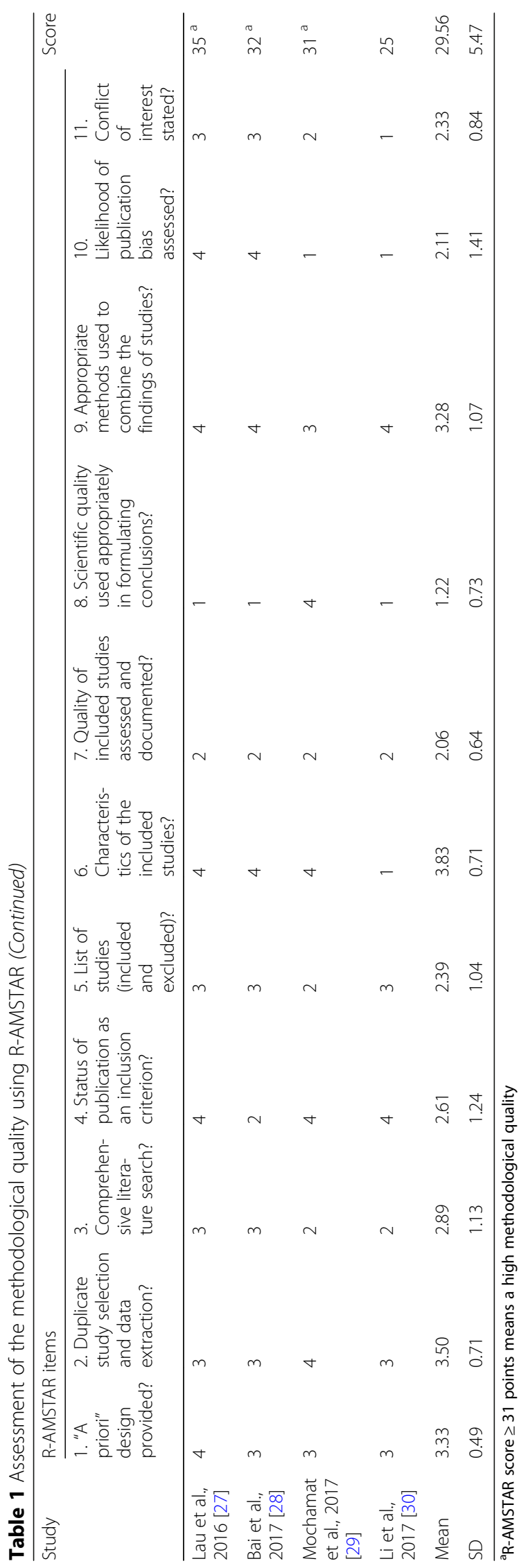


Table $\mathbf{2}$ Characteristics of systematic reviews

\begin{tabular}{|c|c|c|c|c|c|c|}
\hline $\begin{array}{l}\text { Systematic } \\
\text { review }\end{array}$ & $\begin{array}{l}\text { Relevant } \\
\text { studies, } \\
\text { No }\end{array}$ & Study design (No) & Population & Intervention & Control & Outcome \\
\hline $\begin{array}{l}\text { Dewey et } \\
\text { al., } 2007 \\
{[17]}\end{array}$ & 5 & $\mathrm{RCT}(n=5)$ & $\begin{array}{l}\text { Incurable or advanced cancer } \\
\text { patients with either a reported } \\
\text { weight loss of } 5 \% \text { and above } \\
\text { or cachexia }\end{array}$ & $\begin{array}{l}\text { Oral fish oil } \\
\text { supplementation }\end{array}$ & $\begin{array}{l}\text { Placebo/ active } \\
\text { matched control }\end{array}$ & $\begin{array}{l}\text { AE, BC, CR, EE, Fatigue, FS, } \\
\text { NS, PS, QoL, SA, Survival, WC }\end{array}$ \\
\hline $\begin{array}{l}\text { Baldwin et } \\
\text { al., } 2012 \\
\text { [19] }\end{array}$ & 13 & $\mathrm{RCT}(n=13)$ & $\begin{array}{l}\text { Adults cancer patients with } \\
\text { malnourished or at risk of } \\
\text { malnutrition }\end{array}$ & $\begin{array}{l}\text { Dietary advice, oral } \\
\text { nutritional } \\
\text { supplements, or } \\
\text { both }\end{array}$ & Usual care & $\begin{array}{l}\mathrm{Nl} \text { (ie, weight loss and } \\
\text { energy intake), QOL, Survival }\end{array}$ \\
\hline $\begin{array}{l}\text { Reid et al., } \\
2012 \text { [20] }\end{array}$ & 3 & $\mathrm{RCT}(n=3)$ & $\begin{array}{l}\text { Advanced or incurable cancer } \\
\text { patients with weight loss or } \\
\text { cachexia }\end{array}$ & Thalidomide orally & $\begin{array}{l}\text { Placebo/ an } \\
\text { alternative } \\
\text { experimental } \\
\text { treatment modality }\end{array}$ & $\begin{array}{l}\mathrm{AE}, \mathrm{BC} \text {, Fatigue, FS, GP, PIC, } \\
\text { PS, QoL, Survival }\end{array}$ \\
\hline $\begin{array}{l}\text { Ruiz et al., } \\
2013 \text { [21] }\end{array}$ & 35 & $\mathrm{RCT}(n=35)$ & $\begin{array}{l}\text { Patients with cancer, AIDS or } \\
\text { another underlying pathology } \\
\text { related anorexia-cachexia }\end{array}$ & Megestrol acetate & $\begin{array}{l}\text { Placebo/ other } \\
\text { active drug } \\
\text { treatments/ } \\
\text { different doses }\end{array}$ & AC, AE, MAC, QoL, TSFT, WC \\
\hline $\begin{array}{l}\text { Chung et } \\
\text { al., 2016 } \\
{[26]}\end{array}$ & 14 & $\mathrm{RCT}(n=14)$ & $\begin{array}{l}\text { Cancer patients with various } \\
\text { types, most in moderate to } \\
\text { advanced stage }\end{array}$ & $\begin{array}{l}\text { CHM, either in } \\
\text { combination with } \\
\text { other treatments } \\
\text { or used alone }\end{array}$ & $\begin{array}{l}\text { Conventional } \\
\text { treatment, placebo, } \\
\text { or no treatment. }\end{array}$ & $\begin{array}{l}\text { Fatigue, paresthesias, } \\
\text { dysesthesias, chronic pain, } \\
\text { anorexia, insomnia, limbs } \\
\text { edema, constipation }\end{array}$ \\
\hline $\begin{array}{l}\text { Lau et al., } \\
2016[27]\end{array}$ & 13 & $\mathrm{RCT}(n=13)$ & $\begin{array}{l}\text { Patients with various types of } \\
\text { cancer, near half in moderate } \\
\text { to advanced stages }\end{array}$ & $\begin{array}{l}\text { Any form of } \\
\text { acupuncture and/ } \\
\text { or related } \\
\text { therapies }\end{array}$ & $\begin{array}{l}\text { Any type of } \\
\text { interventions } \\
\text { without } \\
\text { acupuncture or } \\
\text { related treatments }\end{array}$ & $\begin{array}{l}\text { Fatigue, paresthesia, } \\
\text { dysesthesias, chronic pain, } \\
\text { anorexia, insomnia, limb } \\
\text { edema, constipation, QoL }\end{array}$ \\
\hline $\begin{array}{l}\text { Bai et al., } \\
2017 \text { [28] }\end{array}$ & 4 & $\begin{array}{l}\mathrm{RCT}(N=3) \\
\text { Randomized } \\
\text { crossover Trial }(n \\
=1)\end{array}$ & $\begin{array}{l}\text { Cancer anorexia-cachexia syn- } \\
\text { drome (CACS) patients }\end{array}$ & Anamorelin & $\begin{array}{l}\text { Placebo or } \\
\text { Anamorelin at } \\
\text { various doses }\end{array}$ & $\begin{array}{l}\text { AC, GS, LBM, PS, QoL, Serum } \\
\text { biomarkers, WC }\end{array}$ \\
\hline $\begin{array}{l}\text { Mochamat } \\
\text { et al., } 2017 \\
\text { [29] }\end{array}$ & 21 & $\begin{array}{l}\text { RCT }(n=17) \\
\text { Prospective } \\
\text { studies }(n=3) \\
\text { Crossover study } \\
(n=1)\end{array}$ & $\begin{array}{l}\text { Cancer patients with cachexia } \\
\text { or cachexia-related symptoms }\end{array}$ & $\begin{array}{l}\text { Vitamin, mineral, } \\
\text { proteins, or other } \\
\text { dietary } \\
\text { supplements }\end{array}$ & $\begin{array}{l}\text { No supplements/ } \\
\text { different } \\
\text { supplements }\end{array}$ & $\begin{array}{l}\text { AE, AC, LBM, L-carnitine, QoL, } \\
\text { Survival, WC, }\end{array}$ \\
\hline
\end{tabular}

Abbreviations: $A C$ appetite change, $A E$ adverse events, $A I D S$ acquired immune deficiency syndrome, $B C$ body composition, $C H M$ chinese herbal medicine, $C R$ compliance rates, $E E$ energy expenditure, FS functional status, GS grip strength, LBM lean body mass, MAC mid-arm circumference, NS nutritional status, NI nutritional indices, PIC pro-inflammatory cytokines, PS performance status, QoL quality of life, RCT randomized clinical trial, SE side effects, TSFT triceps skin fold thickness, WC weight change

lung cancer patients; Adverse events of acupuncture and related therapies were infrequent and mild [27].

\section{Chinese herbal medicine}

Qi-ge-kai-wei decoction plus megestrol acetate versus megestrol acetate alone, showed a higher proportion of reported improvement $(93.8 \%$ vs $87.5 \%)$ for treating anorexia in advanced lung cancer patients; However, there was no statistical significance. Tong-tai decoction and chemotherapy showed more improvement than chemotherapy alone in advanced colorectal cancer patients (55.0\% vs $45.0 \%$ ), but again no significance difference was found; CHM could significantly reduced pain (pooled WMD: -0.90, 95\% CI: -1.69 - 0.11), compared with conventional intervention; Adverse events were infrequent and mild [26].

\section{Eicosapentaenoic acid}

There was no sufficient data to establish whether oral Eicosapentaenoic acid (EPA) was better than placebo. Comparisons of EPA combined with a protein energy supplementation versus a protein energy supplementation (without EPA) in the presence of an appetite stimulant (Megestrol Acetate) provided no evidence that EPA could improve symptoms associated with the cachexia syndrome often seen in patients with advanced cancer [17].

\section{Oral nutritional intervention}

Oral Nutritional intervention (ONI) was associated with statistically significant improvements in weight ( $\mathrm{MD}=1.86 \mathrm{~kg}, 95 \% \mathrm{CI}=0.25 \sim 3.47)$, and energy intake $(\mathrm{MD}=432 \mathrm{kcal} / \mathrm{d}, 95 \% \mathrm{CI}=172 \sim 693)$, compared with routine care; However, after removing the main 
sources of heterogeneity, there was no statistically significant difference in weight gain or energy intake; In addition, ONI had a beneficial effect on some aspects of QoL (emotional functioning, dyspnea, loss of appetite, and global QoL), but had no effect on mortality $(\mathrm{RR}=1.06,95 \% \mathrm{CI}=0.92 \sim 1.22)$ [19].

\section{Vitamins, minerals, proteins, and other supplements}

As far as vitamins were concerned, vitamin $\mathrm{E}$ in combination with omega-3 fatty acids displayed a significant prolonged survival (no exact number presented, $P=$ 0.01) in one RCT, vitamin D showed improvement of muscle weakness $(37 \%)$ in a crossover study, and vitamin C supplementation led to significantly higher scores of various quality of life aspects, such as physical, emotional and cognitive, in a sample with a variety of cancer diagnoses; Regarding minerals, only one study examined the use of magnesium with no effect on weight loss; For proteins, a combination therapy of $\beta$-hydroxy- $\beta$-methylbutyrate (HMB), arginine, and glutamine showed an increase in body weight $(2.27 \pm$ $1.17 \mathrm{~kg}$ vs $0.27 \pm 1.39, P=0.06$ ) after 24 weeks in a study of advanced solid tumour patients, whereas the same combination did not show a benefit on lean body mass (LBM) in a large sample of advanced lung and other cancer patients after 8 weeks; L-carnitine led to an increase of body mass index $(3.4 \pm 1.4 \%$ vs $1.5 \pm 1.4 \%, P<$ 0.05 ) and an increase in overall survival (median $519 \pm$ $50 \mathrm{~d}$ vs $399 \pm 43 \mathrm{~d}, P=\mathrm{ns}$ ) in advanced pancreatic cancer patients; Adverse effects of food supplementation were rare and showed mild intensity [29].

\section{Anamorelin}

Compared with placebo, Anamorelin showed statistically significant improvement in $\mathrm{LBM}(\mathrm{SMD}=0.34,95 \% \mathrm{CI}=$ $0.21 \sim 0.46)$, body weight $(\mathrm{SMD}=1.91,95 \% \mathrm{CI}=0.53 \sim$ 3.29), Anderson Symptom Assessment Scale (ASAS) score $(\mathrm{MD}=8.05,95 \% \mathrm{CI}=5.97 \sim 10.12)$, insulin-like growth factor-1 level $(\mathrm{SMD}=2.51,95 \% \mathrm{CI}=0.37 \sim 4.46)$, IGF binding protein-3 $(\mathrm{SMD}=1.65,95 \% \mathrm{CI}=1.13 \sim$ 2.18). Three studies reported non-dominant handgrip strength, but there was no significant difference (SMD = $0.30,95 \% \mathrm{CI}=-0.12 \sim 0.72$ ). All the included studies reported adverse events, Anamorelin induced fewer adverse events, but there was no significant difference between the two groups $(\mathrm{RR}=0.07, P=0.35)$ [28].

\section{Megestrol acetate}

Megestrol acetae (MA) showed a benefit compared with placebo, particularly with regard to appetite improvement $(\mathrm{RR}=2.57,95 \% \mathrm{CI}=1.41 \sim 3.40)$ and weight gain $(\mathrm{RR}=1.55,95 \% \mathrm{CI}=1.06 \sim 2.26)$ in cancer, but lack of benefit when compared to other drugs. There was insufficient information to define the optimal dose of MA, but higher doses were more related to weight improvement than lower doses; Quality of life improvement in patients was observed only when comparing MA versus placebo $(\mathrm{RR}=1.91,95 \% \mathrm{CI}=1.02 \sim 3.59)$ but not other drugs in cancer. Oedema, thromboembolic phenomena and deaths were more frequent in patients treated with MA [21].

\section{Thalidomide}

A dearth of large, well conducted trials about thalidomide for the management of cancer cachexia. At present, there was insufficient evidence to refute or support the use of thalidomide for the management of cachexia in advanced cancer patients [20].

\section{Discussions}

\section{Quality of evidence}

In general, the methodological quality of the SRs included was moderate with an average R-AMSTAR score of 30 out of 44, and had great room of improvement. Totally the average scores of 5 items of R-AMSTAR were less than 2.4, item 5 "list of studies (included and excluded)?", item 7 "quality of included studies assessed and documented?", item 8 "scientific quality used appropriately in formulating conclusions?", item 10 "likelihood of publication bias assessed?", item 11 "conflict of interest stated?". As for item 5 , most of included SRs failed to meet the criteria of "table/list/figure of excluded studies", and "reader is able to retrace the excluded studies", which needed to pay more attention to; About item 7 and item 8 , most failed to satisfy criteria of "discussion/ recognition/ awareness of level of evidence", "quality of evidence should be rated/ranked based on characterized instruments, e.g. Grading of Recommendations Assessment, Development, Evaluation (GRADE)", "the results of the methodological rigor and scientific quality are explicitly stated in formulation recommendations", "have conclusions integrated/drives towards a clinical consensus statement", and "this clinical consensus statement drives toward revision of confirmation of clinical practice guidelines"; Criteria of "an assessment of publication bias should include graphical aids" and "statistical tests" was not performed by most of included SRs, regarding to item 10; Concerning item 11, most SRs authors did not report "conflict of interest", and "statement of support or conflict of interest in the primary inclusion studies".

\section{Summaries of main findings}

In regard to the management of cancer related anorexia, summaries of 8 SRs with high methodological quality include drugs, dietary or nutritional intervention, CHM, and acupuncture. Anamorelin had some positive effects to relieve cancer anorexia-cachexia syndrome (CACS) 
and improved QoL; However, the heterogeneity was apparent, so the clinical effects of Anamorelin should be further validated by increasing the sample size, varying the range of doses during treatment, and observing other outcomes. Megestrol Acetate (MA) could improve appetite, and was associated with slight weight gain for CACS; Despite of the fact that these patients were receiving palliative care they should be informed of the risks involved in taking MA. Oral nutritional interventions were effective in increasing nutritional intake and improving some aspects of QoL in patients with cancer who were malnourished or at nutritional risk, but did not appear to improve mortality. The use of thalidomide, EPA, and minerals, vitamins, proteins, or other supplements for the treatment of cachexia in cancer was uncertain, and there was inadequate evidence to recommend it for clinical practices, the same situation in $\mathrm{CHM}$ and acupuncture for treating anorexia in cancer patients, warranting further RCTs in these areas; Acupuncture and related therapies were effective in improving quality of life when compared with conventional intervention alone among cancer patients; Limitations on current evidence body imply that they should be used as complements, rather than alternatives, to conventional care.

\section{Strengths and limitations}

Despite the care with which they were conducted, SRs might differ in quality. And yield different answers to the same question [31]. Therefore, users of SRs should be critical and careful at the methodological quality of the available reviews [32]. Thus, only SRs on management of cancer-related anorexia with high methodological quality would be taken into consideration, in order to improve the reliability of results. However, this strategy might hinder us from the chance to get access to RCTs with high quality in SRs not included.

As for the instrument to assess the quality of conduct of systematic reviews of randomised controlled trials of interventions, A Measurement Tool to Assess systematic Reviews (AMSTAR), published in 2007, was one of the most widely used instruments [33, 34]. Researchers had pointed out that AMSTAR had some limitations, and needed to be improved [35, 36]. While R-AMSTAR provided a numerical score of methodological quality for each review, and also met some limitations, e.g. criteria of discussion/recognition/ awareness of the quality of the body of evidence, based on AMSTAR [11]. R-AMSTAR was of more usable and congruent to assess methodological quality of SRs, compared with AMSTAR.

\section{Conclusions}

Our findings of management strategies for patients with cancer-related anorexia suggested that anamorelin, MA, oral nutrition interventions, and acupuncture could be considered to be applied in clinical practices. Future RCTs and SRs with high quality on the pharmaceutical or non-pharmaceutical interventions of anorexia in cancer patients are warranted.

\section{Additional file}

Additional file 1: Search method. (DOCX $14 \mathrm{~kb}$ )

\section{Abbreviations}

AC: Appetite change; AE: Adverse events; AIDS: Acquired immune deficiency syndrome; BC: Aody composition; CACS: Cancer anorexia-cachexia syndrome; CHM: Chinese Herbal Medicine; CR: Compliance rates; EE: Energy expenditure; EPA: Eicosapentaenoic acid; FS: Functional status; GS: Grip strength; LBM: Lean body mass; MA: Megestrol acetae; MAC: Mid-arm circumference; NI: Nutritional indices; NS: Nutritional status; ONI: Oral nutritional intervention; PIC: Pro-inflammatory cytokines; PS: Performance status; QoL: Quality of life; R-AMSATR: Revised Assessment of Multiple Systematic Reviews; RCT: Randomized clinical trial; SE: Side effects; SRs: Systematic reviews; TSFT: Triceps skin fold thickness; WC: Weight change

\section{Acknowledgements}

We thank Chinese Anti-Cancer Association Oncologic Nursing Committee who offering great support for the development of this review.

Funding

The authors received no special funding for this work.

Availability of data and materials

All data generated or analysed during this study are included in this published article.

\section{Authors' contributions}

FY contributed to the study protocol, defined the search strategy, performed the literature search, contributed to the review of the papers for inclusion, quality assessment and data analysis, and drafted the manuscript. AM participated in the literature search, reviewed the papers for inclusion, and participated in the quality assessment of included systematic reviews. YH helped define the search strategy, and draft the manuscript. WM participated in the study protocol, defined the search strategy, and helped draft the manuscript. All authors read and approved the final manuscript.

Ethics approval and consent to participate

Not applicable: a critical review of systematic reviews.

Consent for publication

Not applicable: no individual person's data.

Competing interests

The authors declare that they have no competing interest.

\section{Publisher's Note}

Springer Nature remains neutral with regard to jurisdictional claims in published maps and institutional affiliations.

\section{Author details}

${ }^{1}$ Tianjin Medical University Cancer Institute and Hospital, National Clinical Research Center for Cancer; Key Laboratory of Cancer Prevention and Therapy, Tianjin; Tianjin's Clinical Research Center for Cancer, Tianjin, CN, Hexi District, 1 West Lake Road, Tianjin, China. ${ }^{2}$ Center for Evidence-Based and Translational Medicine, Zhongnan Hospital of Wuhan University, Wuhan, CN, Center for Evidence-Based and Translational Medicine, Wuhan University, Wuhan, China. 
Received: 25 April 2018 Accepted: 1 August 2018

Published online: 09 August 2018

\section{References}

1. Fitzmaurice C, Allen C, Barber RM, et al. Global, regional, and National Cancer Incidence, mortality, years of life lost, years lived with disability, and disability-adjusted life-years for 32 Cancer groups, 1990 to 2015. JAMA Oncol. 2017;3(4):524-48. https://doi.org/10.1001/jamaoncol.2016. 5688.

2. Barbera L, Seow $H$, Howell D, et al. Symptom burden and performance status in a population-based cohort of ambulatory cancer patients. Cancer 2010;116(24):5767-76.

3. Van LA, Velghe A, Van HA, et al. Prevalence of symptoms in older cancer patients receiving palliative care: a systematic review and meta-analysis. J Pain Symptom Manag. 2014;47(1):90-104.

4. Giesinger JM, Wintner LM, Oberguggenberger AS, et al. Quality of life trajectory in patients with advanced cancer during the last year of life. J Palliat Med. 2011;14(8):904-12.

5. Reeve BB, Mitchell SA, Dueck AC, et al. Recommended patient-reported core set of symptoms to measure in adult cancer treatment trials. J Natl Cancer Inst. 2014;106(7):1-8.

6. Yavuzsen T, Davis MP, Walsh D, et al. Systematic review of the treatment of cancer-associated anorexia and weight loss. J Clin Oncol. 2005;23(33):8500-11.

7. Tarricone R, Ricca G, Nyanzi WB, et al. Impact of cancer anorexia-cachexia syndrome on health-related quality of life and resource utilisation: a systematic review. Crit Rev Oncol Hematol. 2016;99:49-62.

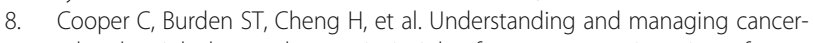
related weight loss and anorexia: insights from a systematic review of qualitative research. J Cachexia Sarcopenia Muscle. 2015;6(1):99-111.

9. Trajkovic-Vidakovic M, de Graeff A, Voest EE, et al. Symptoms tell it all: a systematic review of the value of symptom assessment to predict survival in advanced cancer patients. Crit Rev Oncol Hematol. 2012;84(1):130-48.

10. Shea BJ, Reeves BC, Wells G, et al. AMSTAR 2: a critical appraisal tool for systematic reviews that include randomised or non-randomised studies of healthcare interventions, or both. BMJ. 2017;358:j4008.

11. Kung J, Chiappelli F, Cajulis OO, et al. From systematic reviews to clinical recommendations for evidence-based health care: validation of revised assessment of multiple systematic reviews (R-AMSTAR) for grading of clinical relevance. Open Dent J. 2010:4:84-91.

12. Pinnock $H$, Parke $H L$, Panagioti $M$, et al. Systematic meta-review of supported self-management for asthma: a healthcare perspective. BMC Med. 2017;15(64):1-32.

13. Kowalczuk M, Adamich J, Simunovic N, et al. Methodological quality of systematic reviews addressing femoroacetabular impingement. Knee Surg Sports Traumatol Arthrosc. 2015;23(9):2583-9.

14. Maltoni M, Nanni O, Scarpi E, et al. High-dose progestins for the treatment of cancer anorexia-cachexia syndrome: a systematic review of randomised clinical trials. Ann Oncol. 2001;12(3):289-300

15. Pascual LA, Roque IFM, Urrutia CG, et al. Systematic review of megestrol acetate in the treatment of anorexia-cachexia syndrome. J Pain Symptom Manag. 2004;27(4):360-9.

16. Berenstein EG, Ortiz Z. Megestrol acetate for the treatment of anorexiacachexia syndrome. Cochrane Database Syst Rev. 2005;2:CD004310.

17. Ann D, Chris B, Dean TP, et al. Eicosapentaenoic acid (EPA, an omega-3 fatty acid from fish oils) for the treatment of cancer cachexia. Cochrane Database Syst Rev. 2007;1:CD004597.

18. Wiktoria L, Malgorzata B, Roman J, et al. Effects of megestrol acetate in patients with cancer anorexia-cachexia syndrome: a systematic review and meta-analysis. Pol Arch Med Wewn. 2008;118(11):636-44.

19. Baldwin C, Spiro A, Ahern R, et al. Oral nutritional interventions in malnourished patients with cancer: a systematic review and meta-analysis. J Natl Cancer Inst. 2012;104(5):371-85.

20. Reid J, Mills M, Cantwell M, et al. Thalidomide for managing cancer cachexia. Cochrane Database Syst Rev. 2012;4:CD008664.

21. Ruiz GV, Lopez-Briz E, Carbonell SR, et al. Megestrol acetate for treatment of anorexia-cachexia syndrome. Cochrane Database Syst Rev. 2013;3:CD004310.

22. Payne C, Larkin PJ, Mcllfatrick S, et al. Exercise and nutrition interventions in advanced lung cancer: a systematic review. Curr Oncol. 2013;20(4):e321-37.

23. Reid J, Hughes CM, Murray L, et al. Cantwell MM. Non-steroidal antiinflammatory drugs for the treatment of cancer cachexia: a systematic review. Palliative Med. 2013;27(4):295-303.
24. Solheim TS, Fearon KC, Blum D, et al. Non-steroidal anti-inflammatory treatment in cancer cachexia: a systematic literature review. Acta Oncol. 2013;52(1):6-17.

25. Miller S, McNutt L, McCann MA, et al. Use of corticosteroids for anorexia in palliative medicine: a systematic review. J Palliat Med. 2014;17(4):482-5.

26. Chung VC, Wu X, Lu P, et al. Chinese herbal medicine for symptom Management in Cancer Palliative Care: systematic review and Meta-analysis. Medicine (Baltimore). 2016;95(7):e2793.

27. Lau CHY, Wu X, Chung VCH, et al. Acupuncture and related therapies for symptom management in palliative cancer care: systematic review and meta-analysis. Medicine (Baltimore). 2016;95(9):e2901.

28. Bai $Y, H u Y, Z$ hao $Y$, et al. Anamorelin for cancer anorexia-cachexia syndrome: a systematic review and meta-analysis. Support Care Cancer. 2017;25(5):1651-9.

29. Mochamat, Cuhls $\mathrm{H}$, Marinova $\mathrm{M}$, et al. A systematic review on the role of vitamins, minerals, proteins, and other supplements for the treatment of cachexia in cancer: a European palliative care research Centre cachexia project. J Cachexia Sarcopenia Muscle. 2017;8(1):25-39.

30. Li S, Ma H, Li S. Review and Meta-analysis of the $\omega-3$ polyunsaturated fatly acid for cancer cechexia treatment. Changnei Yu Changwai Yingyang. 2017; 24(1):28-32.

31. Moher D, Soeken K, Sampson M, et al. Assessing the quality of reports of systematic reviews in pediatric complementary and alternative medicine. BMC Pediatr. 2002;2(3):1-8.

32. Jadad AR, Moher M, Browman GP, et al. Systematic reviews and metaanalyses on treatment of asthma: critical evaluation. BMJ. 2000;320(7234): 537-40.

33. Shea BJ, Hamel C, Wells GA, et al. AMSTAR is a reliable and valid measurement tool to assess the methodological quality of systematic reviews. J Clin Epidemiol. 2009;62(10):1013-20.

34. Shea BJ, Grimshaw JM, Wells GA, et al. Development of AMSTAR: a measurement tool to assess the methodological quality of systematic reviews. BMC Med Res Methodol. 2007;7:10.

35. Burda BU, Holmer HK, Norris SL. Limitations of a measurement tool to assess systematic reviews (AMSTAR) and suggestions for improvement. Syst Rev. 2016;5:58.

36. Wegewitz $U$, Weikert B, Fishta A, et al. Resuming the discussion of AMSTAR: what can (should) be made better? BMC Med Res Methodol. 2016;16(1):111.

\section{Ready to submit your research? Choose BMC and benefit from:}

- fast, convenient online submission

- thorough peer review by experienced researchers in your field

- rapid publication on acceptance

- support for research data, including large and complex data types

- gold Open Access which fosters wider collaboration and increased citations

- maximum visibility for your research: over $100 \mathrm{M}$ website views per year

At $\mathrm{BMC}$, research is always in progress.

Learn more biomedcentral.com/submissions 